\title{
Effects of using potassium adsorption filters on saline- filled and saline-removed methods for the removal of potassium from red blood cell solutions
}

Hiroshi Fujita ${ }^{1 *}$, Yoko Shiotani ${ }^{2}$, Yuko Takada ${ }^{2}$ and Shigeko Nishimura ${ }^{1}$

*Correspondence: hiroshi_fujita@tmhp.jp

CrossMark

$\leftarrow$ Click for updates

'Department of Transfusion Medicine, Tokyo Metropolitan Bokutoh Hospital, Tokyo, Japan.

${ }^{2}$ Clinical Laboratory, Tokyo Metropolitan Bokutoh Hospital, Tokyo, Japan.

\begin{abstract}
Introduction: Red blood cell (RBC) transfusion places preterm infants with non-oliguria at high risk of cardiac arrest due to hyperkalemia. Potassium adsorption filters (PAFs) can remove potassium from RBCs. The typical protocol for use of PAFs in Japan involves priming the filter with $200 \mathrm{~mL}$ of saline and filling the filter with saline However, the resulting dead volume (approximately $80 \mathrm{~mL}$ ) is unnecessary in preterm infants, because the blood is diluted with saline. As transfusion volumes are generally $\sim 10 \mathrm{~mL}$, small volume-separated packs $(30 \sim 80 \mathrm{~mL}$ each) are prepared for preterm infants. However, we are unable to use PAFs in small volume-separated packs due to the dead volume. In this study, we examined the effects of saline-filled and saline-removed methods of PAFs on the removal of potassium from RBCs.

Method: The experiments used expired RBCs from our hospital. RBC potassium, lactate dehydrogenase (LD) and free hemoglobin (markers of erythrocyte damage) were measured by Biomedical Laboratories and compared with levels of RBCs passed through a PAF (KPF-1, Kawasumi Laboratories Incorporated). After priming PAFs with $200 \mathrm{~mL}$ of saline, saline was filled (method A) or was removed (method B) before use of the PAF. This study was supported by a grant from the Tokyo Metropolitan Government.
\end{abstract}

Results: The percent removal of potassium from the RBC for method A (89 93\%) was similar to that of method B (95 98\%). LD and free hemoglobin levels in method A were lower than those in method B. However, the increased LD and free hemoglobin levels were similar to those of transfusion filters. Potassium in the small volume-separated pack was completely removed by method B.

Discussion: The effects of saline-filled and saline-removed methods of PAF usage on the removal of potassium from RBC were similar, with little erythrocyte damage. These data suggest that PAF might be used for small volume-separated packs in the neonatal ward.

Keywords: Donor exposure, neonate transfusion, hyperkalemia

\section{Introduction}

Because preterm infants with anemia usually receive frequent transfusions of small volumes of separated blood, they are often exposed to blood from many donors. In the neonatal intensive care units, multiple small volume-separated packs are divided from a standard unit of red blood cell (RBC) solution from a single donor andare transfused to the infant [1].

Preterm infants with non-oliguric hyperkalemia and neonates receiving massive transfusions are at high risk of cardiac arrest due to hyperkalemia during transfusion [2-5]. Potassium levels in the RBC solution increase with increased storage time [6]. Therefore, washed RBCs are often used for massive neonate transfusions in order to avoid the potassium load [7]. Potassium adsorption filters (PAFs), which areused at the bedside, can also remove potassium from RBC solutions [8-12]. In Japan, after priming the PAFswith $200 \mathrm{~mL}$ of saline, saline is re-filled before use of the PAFs. However, the resulting dead volume (approximately $80 \mathrm{~mL}$ of saline) is unnecessary for preterm infants, because 
Fujita et al. Medical Instrumentation 2016,

the blood is diluted with saline. As the transfusion volume is $\sim 10 \mathrm{~mL}$, small volume-separated packs (30 80m Leach) are prepared for preterm infants [1]. However, PAFs cannot be used for small-volume separated packs due to the presence of the dead volume, when RBC are administered topreterm infants with non-oliguric hyperkalemia. We speculated that PAFs may be available for use after removing the filled saline after priming. In this study, the effects of saline-filled and saline-removed PAF methods were examined on the removal of potassium from RBC solutions. The saline-removed method for PAF was more effective than the standard saline-filled method. This method might be useful for RBC transfusion of small volume-separated packs.

\section{Materials and methods Blood products}

The blood products including RBCs (Japan Red Cross Society, Tokyo, Japan) used in the experiments in our hospital were expired. In Japan, RBCs should be used within 21 days.

\section{Methods}

After the PAFs (KPF-1, Kawasumi Laboratories Incorporated, Oita, Japan) were primed with $250 \mathrm{ml}$ of saline (Terumo Corporation, Tokyo, Japan), they were filled with approximately $80 \mathrm{ml}$ of saline (method A) or the saline was removed (method B) before use of PAF. Two units of RBCs were divided into two bags ( $140 \mathrm{~mL}$ per unit). One unit of RBC solution $(140 \mathrm{~mL})$ was filtered with a flow rate of approximately $20 \mathrm{~mL} /$ minute and collected into empty bags. Potassium and ammonia concentrations in the RBC collected in the empty bags were measured by Biomedical Laboratories Company (Tokyo, Japan) and compared to those in the RBC pre-PAF.

Percent removal (\% removal) was defined as follows: Percent removal (\% removal) $=$ (mean potassium value in the $\mathrm{RBC}$ before use of the PAF-potassium value in the RBC after use of the PAF) $\div$ mean potassium value in the $\mathrm{RBC}$ before use of PAFx100 (\%).

In the experiments using RBC solutions, hemoglobin concentration and hematocrit were measured in order to determine the effect of dilution due to residual saline.

\section{Erythrocyte damage}

In order to evaluate erythrocyte damage, lactate dehydrogenase (LD) and free hemoglobin were measured by Biomedical Laboratories Company (Tokyo, Japan). The differences in erythrocyte damage following PAF using method B were compared to the one using a transfusion filter (Terumo Corporation, Tokyo, Japan).

\section{Preparation of small volume-separated packs}

Four small volume-separated packs (BB-TQ009J, Terumo Corporation, Tokyo, Japan) were divided from 1 unit of RBC using a Terumo Sterile Connection Device-II (Terumo Corporation, Tokyo, Japan). Each pack contained approximately
$35 \mathrm{~mL}$ of RBCs. RBCs in three small volume-separated packs were filtered at a flow rate of approximately $20 \mathrm{~mL} /$ minute and collected into empty bags using method $B$. The fourth volume-separated RBC was used as the pre-PAF control. The study design was approved by the ethics review board of our institution.

\section{Statistical analysis}

The differences in potassium concentrations between samples before and after PAF were compared by using Wilcoxon's analysis. Data were expressed as group means \pm standard errors of the mean. All statistical calculations were performed using JMP version 8.0 (SAS Institute, Inc., Cary, NC), and statistical significance was defined as $p<0.05$.

\section{Results}

The effects of saline-filled (A) and a saline-removed (B) potassium adsorption filter methodson potassium concentrations

The standard saline-filled (A) method used in Japan for PAF resulted in the removal of $89.7-93.1 \%$ of potassium from the RBC, as shown in Table 1. In comparison, the saline-removed PAF method (B) also removed $95.1-96.8 \%$ of the potassium. The $\%$ removal of potassium by PAF using a method $B$ method was significantly higher than that by method $A$, as shown in Table 1.

Hemoglobin and hematocrit levels did not decrease in the RBC solution after using PAF method B (RBC \#2 in Table 1; pre-hemoglobin: $20.8 \pm 0.0 \mathrm{~g} / \mathrm{dL}$, pre-hematocrit: $58.1 \pm 0.0 \%$; post-hemoglobin: $20.8 \pm 0.0 \mathrm{~g} / \mathrm{dL}$, post-hematocrit: $58.4 \pm 0.1 \%$, $\mathrm{N}=4$ ), while hemoglobin and hematocrit levels decreased significantly in the RBC solution following PAF method $A$ (RBC \#2 in Table 1; (pre-hemoglobin: $19.1 \pm 0.0 \mathrm{~g} / \mathrm{dL}$, pre-hematocrit: $54.3 \pm 0.1 \%$; post-hemoglobin: $17.2 \pm 0.0 \mathrm{~g} / \mathrm{dL}$, post-hematocrit: $49.6 \pm 0.2 \%, \mathrm{p}<0.05, \mathrm{~N}=4)$. The changes in hemoglobin and hematocrit levels in the other RBC solutions (\#1and \#3) were the same as those in RBC \#2 (data not shown).

Table 1. Effects of potassium adsorption filter methods A and B on potassium concentrations in red blood cell solutions.

\begin{tabular}{llll}
\hline & $\begin{array}{l}\text { Irradiated } \\
\text { RBC \# 1 }\end{array}$ & $\begin{array}{l}\text { Irradiated } \\
\text { RBC \#2 }\end{array}$ & $\begin{array}{l}\text { Irradiated } \\
\text { RBC \#3 }\end{array}$ \\
\hline $\begin{array}{l}\text { Saline-filled method } \\
\text { (method A, N=4) }\end{array}$ & $92.7 \pm 0.1 \%$ & $93.1 \pm 0.0 \%$ & $89.7 \pm 0.1 \%$ \\
$\begin{array}{l}\text { Saline-removed } \\
\text { method } \\
\text { (method B, N=4) }\end{array}$ & $96.8 \pm 0.0 \%^{*}$ & $95.8 \pm 0.0 \%^{*}$ & $95.1 \pm 0.0 \%^{*}$ \\
\hline
\end{tabular}

RBC: Red blood cell solution

The potassium concentration of RBC\#1 (AB type, Rh D+, day 25), RBC\#2 (AB type, Rh D+, day 24), RBC\#3 (AB type, Rh D+, day 24) prior to passing through PAF was $54.0 \pm 1.0 \mathrm{mEq} / \mathrm{L}, 62.8 \pm 2.8$ $\mathrm{mEq} / \mathrm{L}, 60.0 \pm 0.4 \mathrm{mEq} / \mathrm{L}$, respectively.

Data represent the means \pm standard errors.

${ }^{*}$ : $\mathrm{p}<0.05$ vs. values from the sample obtained using method A. 
RBC erythrocyte damage after PAF methods A and B Erythrocyte damage, as assessed by levels of free hemoglobin and LDin the RBC, was higher for method $B$ compared to method A, as shown in Table 2. However, erythrocyte damage in the RBC using method $B$ was almost similar that ofa transfusion filter usually used at transfusion, as shown in Table 3.

Table 2. Erythrocyte damage in the RBC following use of potassium adsorption filters using methods $A$ and $B$.

\begin{tabular}{llll}
\hline & $\begin{array}{l}\text { Irradiated } \\
\text { RBC\# 1 }\end{array}$ & $\begin{array}{l}\text { Irradiated } \\
\text { RBC\#2 }\end{array}$ & $\begin{array}{l}\text { Irradiated } \\
\text { RBC\#3 }\end{array}$ \\
\hline $\begin{array}{l}\text { Saline-filled method } \\
\text { (A) method }\end{array}$ & & & \\
Pre-PAF & & & \\
Free hemoglobin (mg/dL) & $12.3 \pm 2.3$ & $42.3 \pm 0.8$ & $10.0 \pm 0.4$ \\
LD (IU/L) & $42.3 \pm 0.9$ & $112.8 \pm 1.7$ & $48.0 \pm 0.7$ \\
Post-PAF & & & \\
Free hemoglobin (mg/dL) & $12.3 \pm 0.3$ & $44.2 \pm 0.5$ & $10.8 \pm 0.5$ \\
LD (IU/L) & $47.5 \pm 4.1$ & $125.8 \pm 1.5^{*}$ & $47.0 \pm 0.8$ \\
\hline
\end{tabular}

\section{Saline-removed method}

(B) method

Pre-PAF

$\begin{array}{llll}\text { Free hemoglobin }(\mathrm{mg} / \mathrm{dL}) & 12.7 \pm 1.1 & 67.3 \pm 0.8 & 12.0 \pm 0.4\end{array}$

$\begin{array}{llll}\mathrm{LD}(\mathrm{IU} / \mathrm{L}) & 47.8 \pm 0.75 & 193.5 \pm 0.9 & 51.0 \pm 0.0\end{array}$

Post-PAF

$\begin{array}{llll}\text { Free hemoglobin }(\mathrm{mg} / \mathrm{dL}) & 17.5 \pm 0.3^{*} & 82.0 \pm 1.1^{\star} & 14.0 \pm 0.4^{\star}\end{array}$

$\begin{array}{llll}\mathrm{LD}(\mathrm{IU} / \mathrm{L}) & 55.5 \pm 0.3^{*} & 272.2 \pm 5.4^{*} & 60.2 \pm 2.6^{*}\end{array}$

RBC: Red blood cell solution; Data represent the means \pm standard errors.; ${ }^{*}: \mathrm{p}<0.05$ vs. values from the sample prior to passing through the PAF.

Table 3. Erythrocyte damage in red blood cell solutions after use of transfusion and potassium (B method) filters.

\begin{tabular}{|c|c|c|}
\hline & Before filter & After filter \\
\hline \multicolumn{3}{|l|}{ Transfusion filter } \\
\hline Free hemoglobin (mg/dL) & $12.0 \pm 0.0$ & $16.5 \pm 0.6^{*}$ \\
\hline $\mathrm{LD}(\mathrm{IU} / \mathrm{L})$ & $58.0 \pm 0.9$ & $65.0 \pm 0.4^{*}$ \\
\hline \multicolumn{3}{|l|}{$\begin{array}{l}\text { Potassium adsorption filter } \\
\text { (B method) }\end{array}$} \\
\hline Free hemoglobin (mg/dL) & $10.5 \pm 0.3$ & $13.8 \pm 0.5^{*}$ \\
\hline $\mathrm{LD}(\mathrm{IU} / \mathrm{L})$ & $54.0 \pm 1.4$ & $61.3 \pm 0.8^{*}$ \\
\hline
\end{tabular}

The results are representive of 3 independent experiments. Data represent the means \pm standard errors.

${ }^{*}$ : $\mathrm{p}<0.05$ vs. values from the sample prior to passing through transfusion filter or PAF.

Effects of saline-removed PAF method $B$ on potassium concentrations in small volume-separated $\mathrm{RBC}$ packs One unit of RBC was divided into three small volume-separated packs, each containing $35 \mathrm{~mL}$ of RBCs. The $\%$ removal of potassium in the three small volume-separated packs was $96.0 \pm 0.1 \%, 95.9 \pm 0.1 \%$, and $95.7 \pm 0.1 \%$, respectively.

\section{Discussion}

Gupta et al, 2004, reported that eight and four packs per infant offered optimal cost and safety for those with birth weights
$<1000 \mathrm{~g}$ and $>1000 \mathrm{~g}$, respectively [1]. Because neonatal transfusion practice has changed due to restrictive transfusion guidelines, micro-sampling methods, and the practice of delayed cord clamping, separate recommendations were made for infants with birth weights $<1000 \mathrm{~g}$ [13]. Recently, a single unit of RBCs is divided into four small-volume packs in our hospital, each containing approximately $35 \mathrm{~mL}$ of RBCs [13]. Because neonates with non-oliguric hyperkalemiamay develop a lethal arrhythmia, we administer glucose-insulin therapy to reduce serum levelsof potassium and avoid potassium load. To reduce potassium load during RBC transfusion, washed RBCs have been used [7]. However, few hospitals in Japan have the ability to wash RBCs. The potential of PAFs to be a beneficial bedside tool for neonates with non-oliguric hyperkalemia were examined. In Japan, after priming PAFs with $200 \mathrm{~mL}$ of saline, the saline is filled before use of the PAF. The resulting, dead volume (approximately $80 \mathrm{~mL}$ of saline) is unnecessary for preterm infants because the blood is diluted with saline. By removing the saline from the priming, neonates with non-oliguric hyperkalemia may receive small volume-separated packs passed through PAFs. We compared the effectiveness of PAFs for removing potassium between saline-filled and saline-removed methods. The saline-removed PAF method was more effective for removing potassium compared to the saline-filled method, as shown in Table 1. The erythrocyte damage in the RBC passing through PAF using the saline-removed method might be similar to that of the saline-filled method, because the damage using the saline-removed method was similar to that of transfusion filters. PAFs consist of two filters:one filter similar to transfusion filters, and aresin filter that adsorbs potassium. Therefore, we believe the saline-filled PAF method tobe safe.

Moreover, RBC in the small volume-separated pack could be passed through PAF, and the potassium concentrations were removed adequately.

Future studies will examine the effects of the saline-removed PAF on potassium levels of RBCs with in the expiration datesin order to assess the use fulness of this method in the clinical setting.

\section{Conclusion}

PAF using a saline-removal method was more effective than the standard saline-filled method. The saline-removed method might useful for RBC transfusion of small volume-separated packs.

\section{Competing interests}

The authors declare that they have no competing interests.

Authors' contributions

\begin{tabular}{|l|c|c|c|c|}
\hline Authors' contributions & HF & YS & YT & SN \\
\hline Research concept and design & $\checkmark$ & -- & -- & $\checkmark$ \\
\hline Collection and/or assembly of data & -- & $\checkmark$ & $\checkmark$ & -- \\
\hline Data analysis and interpretation & -- & $\checkmark$ & $\checkmark$ & -- \\
\hline Writing the article & $\checkmark$ & -- & -- & -- \\
\hline Critical revision of the article & $\checkmark$ & -- & -- & -- \\
\hline Final approval of article & $\checkmark$ & $\checkmark$ & $\checkmark$ & $\checkmark$ \\
\hline
\end{tabular}


Fujita et al. Medical Instrumentation 2016,

\section{Acknowledgement}

This study was supported by a grant from the Tokyo Metropolitan Government.

\section{Publication history}

Editor: Ioannis G. Valais, Technological Educational Institute, Greece.

Received: 07-Aug-2016 Final Revised: 07-Sep-2016

Accepted: 23-Sep-2016 Published: 03-Oct-2016

\section{References}

1. Gupta A, Patel R and Dyke M. Cost effective use of satellite packs in neonates: importance of birth weight. Arch Dis Child Fetal Neonatal Ed. 2004; 89:F182-3. | Article | PubMed Abstract | PubMed FullText

2. Lorenz JM, Kleinman $\mathrm{LI}$ and Markarian K. Potassium metabolism in extremely low birth weight infants in the first week of life. J Pediatr. 1997; 131:81-6. | Article I PubMed

3. Sato $\mathrm{K}$, Kondo $\mathrm{T}$, Iwao $\mathrm{H}$, Honda $\mathrm{S}$ and Ueda $\mathrm{K}$. Internal potassium shift in premature infants: cause of nonoliguric hyperkalemia. J Pediatr. 1995; 126:109-13. | Article | PubMed

4. Yaseen $\mathrm{H}$. Nonoliguric hyperkalemia in neonates: a case-controlled study. Am J Perinatol. 2009; 26:185-9. | Article | PubMed

5. Lee AC, Reduque LL, Luban NL, Ness PM, Anton B and Heitmiller ES. Transfusion-associated hyperkalemic cardiac arrest in pediatric patients receiving massive transfusion. Transfusion. 2014; 54:244-54. | Article | PubMed

6. Wallas $\mathrm{CH}$. Sodium and potassium changes in blood bank stored human erythrocytes. Transfusion. 1979; 19:210-5. | Article | PubMed

7. Huber D, Witt L, Sumpelmann R, Heinze L, Muller T, Lichtinghagen R and Osthaus WA. Comparison of bicarbonate-buffered fluid and isotonic saline solution as Cell Saver washing fluids for packed red blood cells. Paediatr Anaesth. 2013; 23:1021-6. | Article | PubMed

8. Inaba S, Nibu K, Takano H, Maeda Y, Uehara K, Oshige T, Yuasa T and Nakashima H. Potassium-adsorption filter for RBC transfusion: a phase III clinical trial. Transfusion. 2000; 40:1469-74. | Article | PubMed

9. Yamada C, Heitmiller ES, Ness PM and King KE. Reduction in potassium concentration of stored red blood cell units using a resin filter. Transfusion. 2010; 50:1926-33. | Article | PubMed

10. Matsuura H, Akatsuka Y, Muramatsu C, Isogai S, Sugiura Y, Arakawa S, Murayama M, Kurahashi M, Takasuga H, Oshige T, Yuba T, Mizuta S and Emi N. Evaluation of the potassium adsorption capacity of a potassium adsorption filter during rapid blood transfusion. Vox Sang. 2015; 108:428-31. | Article | PubMed

11. Cid J, Ramiro L, Bertran S, Martinez N, Claparols M, Maymo RM, Puig $\mathrm{L}$ and Pla RP. Efficacy in reducing potassium load in irradiated red cell bags with a potassium adsorption filter. Transfusion. 2008; 48:1966-70. | Article | PubMed

12. Morrison A, McMillan L, Campbell JD and Petrik J. Evaluation of a potassium removal filter on irradiated red cells stored in SAGM. Transfus Med. 2015; 25:320-5. | Article | PubMed

13. Prasad L, Bhatty A and Banerjee S. Donor Exposure in neonatal blood transfusion - Time to change strategy? Arch Dis Child. 2012; 97:A84. Article

\section{Citation:}

Fujita H, Shiotani Y, Takada Y and Nishimura S. Effects of using potassium adsorption filters on saline-filled and saline-removed methods for the removal of potassium from red blood cell solutions. Med Instrum. 2016; 4:1. http://dx.doi.org/10.7243/2052-6962-4-1 